\title{
Impact of Cargo Distribution on the Vehicle Flatback on Braking Distance in Road Freight Transport
}

\author{
Tomáš Skrúcaný ${ }^{1, *}$, Ján Vrábel $^{1}$, Martin Kendra ${ }^{1}$, and Patrik Kažimír ${ }^{1}$ \\ ${ }^{1}$ University of Žilina, Faculty of Operation and Economics of Transport and Communications, \\ Univerzitná 8215/1, 01026 Žilina, Slovakia
}

\begin{abstract}
Vehicle centre of gravity influences directly the breaking characteristics. It dues through the actual each axle load and the actual gross weight of the vehicle. This fact is significant by full braking maneuver. Full braking measurements with different operational vehicle conditions - cargo weight and its location on the vehicle - were done to evaluate this influence. The medium sized good vehicle (category N2) was breaking on a wet asphalt surface. The value of the braking deceleration MFDD and the braking distance was measured by vehicle decelerometer. The results compare different axle- and vehicle load and show the area for future related measurements.
\end{abstract}

\section{Introduction}

Braking plays a key role in critical situations like the early stop in front of an obstacle or its avoidance. In road freight transport, in which trucks weigh tens of tonnes, it prevents causing damage on the vehicle, carried goods, property and what the most important, it can save lives. Having the knowledge of the variables that affect braking can thus help us to avoid these undesirable circumstances.

From the point of view of road safety, the most important is the track needed to stop a vehicle. It is composed of several parts.

The driver response time $t_{r}$ is different for each person, it is influenced by driver's concentration, physical and mental state. The lowest response time of $0.6-0.7 \mathrm{~s}$ is for the driver who is concentrated; the highest time of up to 2 seconds is for a tired driver.

During the delay time of brake effect $t_{d}$, it happens to set off of backlash in braking system mechanism. It takes values of $0.05 \mathrm{~s}$ for hydraulic braking systems and $0.15 \mathrm{~s}$ for pneumatic braking systems.

Throughout the time to develop fully brake effect $t_{d f}$, the increasing pressure in the transfer medium and the permissible deformation of the brake system parts occur. It takes values of $0.15 \mathrm{~s}$ for hydraulic braking systems and $0.2 \mathrm{~s}$ for pneumatic braking systems.

The time of fully brake effect $t_{f}$ flows from the moment the brake reaches its full braking effect until the vehicle stops.

*Corresponding authors: tomas.skrucany@,fpedas.uniza.sk 
However, the actual deceleration of the vehicle during braking is more complicated than the ideal one because of the changes in the brakes temperature, vehicle speed and tire slip ratio.

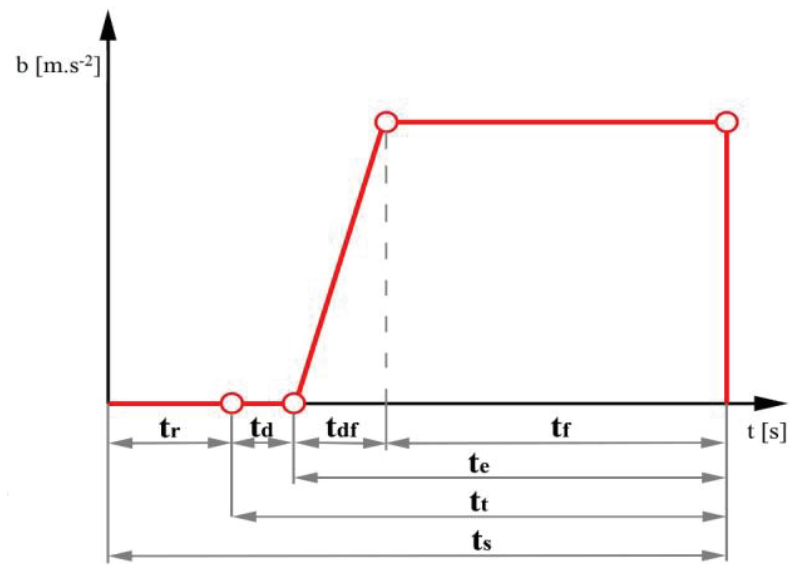

Fig. 1. Braking time process. Source: authors

Legend:

$t_{r}-$ driver response time (s)

$t_{d}$ - brake effect delay time (s)

$t_{d f}$ - time to develop fully braking effect (s)

$t_{f}$ - time of fully braking effect (s)

$t_{e}$ - effective braking time (s)

$t_{t}$ - total braking time (s)

$t_{s}$ - time to stop vehicle (s)

\section{Measurement procedure}

To find out the answers a good vehicle of the N2 category, the MAN TGL 8.180, on which the decelerometer measured brake characteristics during the braking tests, was used.

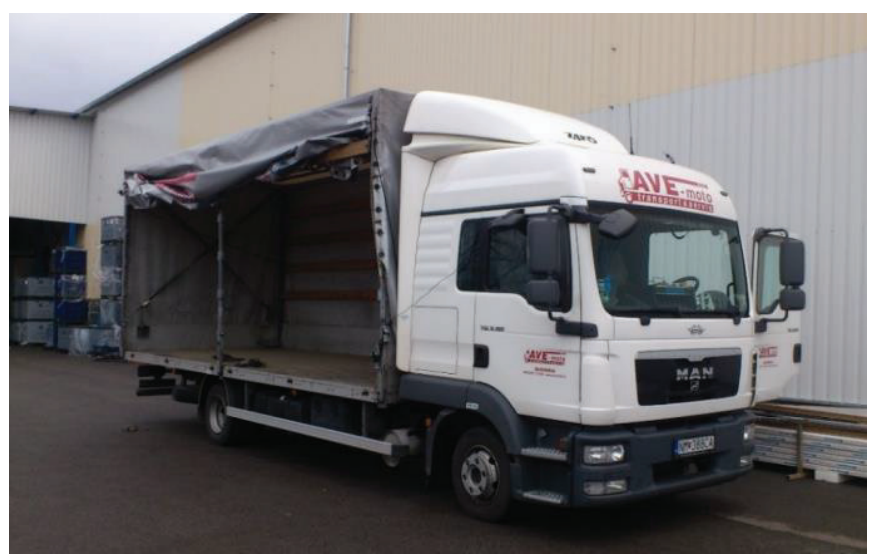

Fig. 2. MAN TGL 8.180. Source: authors

The tests were divided into four situations with a different load distribution on the vehicle's loading surface in the following order: from the first situation - highest front axle load to the fourth position - highest rear axle load. The differently placed cargo caused a 
different axle load and this was measured by the portable weighing system. In addition to the four different axle loads, the impact of the initial vehicle speed at $40 \mathrm{~km} \cdot \mathrm{h}^{-1}, 65 \mathrm{~km} . \mathrm{h}^{-1}$, $80 \mathrm{~km} \cdot \mathrm{h}^{-1}$ was also investigated. Overall, 32 brake tests were planned.

The aim was to find out how mean fully developed deceleration called also MFDD (m.s ${ }^{2}$ ) and braking distance (m) would change. The decelerometer mounted at the front of the load compartment calculated these values automatically after each braking.

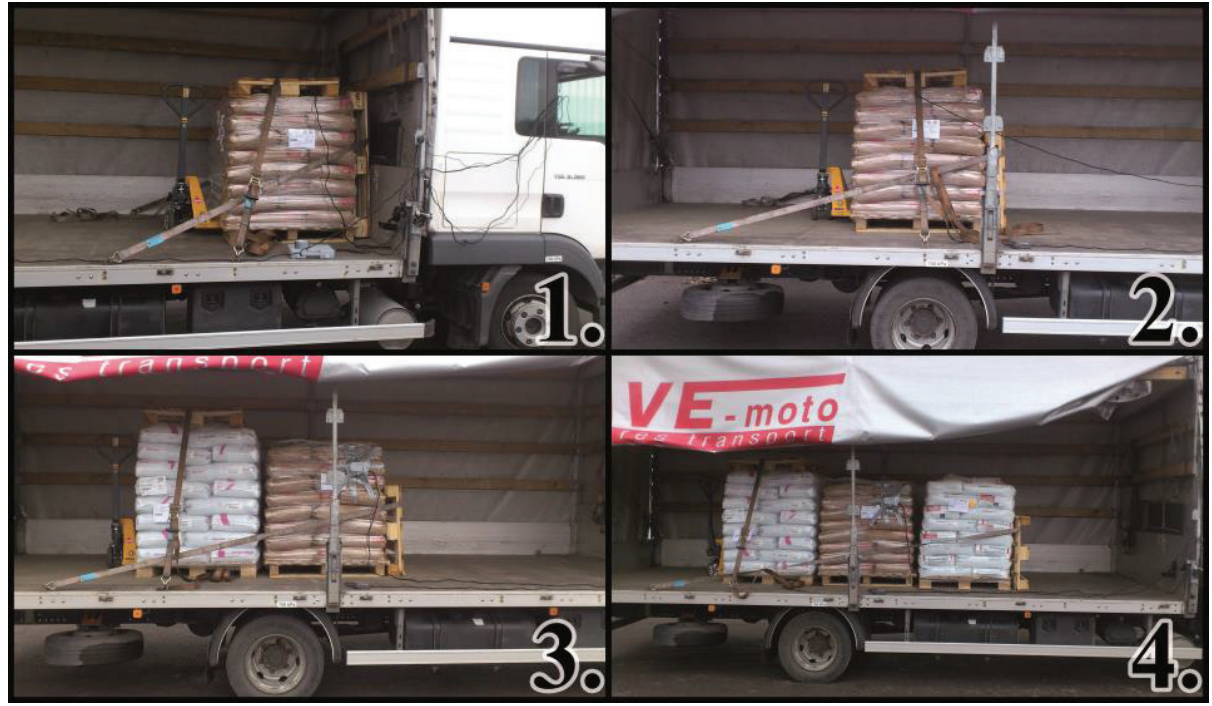

Fig. 3. The cargo distribution on the loading surface in the individual situations. Source: authors

Based on the knowledge of maximum allowable axle load, the maximum pay-mass and the dimensions of the car used, a load distribution diagram was developed. The load in specific situations is also shown on the diagram.

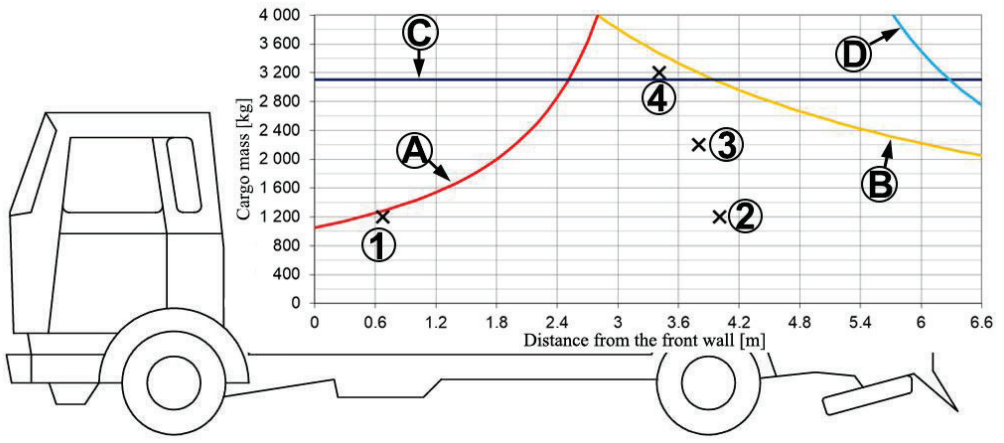

Fig. 4. Load distribution diagram of MAN TGL 8.180. Source: authors

Legend:

A - maximum permissible front axle load

$\mathrm{B}$ - maximum permissible rear axle load

$\mathrm{C}-$ maximum pay-mass

D - minimum front axle load

1 - load in 1st situation

2 - load in 2nd situation

3 - load in 3rd situation

$4-$ load in 4th situation 
When loading, the maximum pay-mass and the maximum permissible axle load must not be exceeded, while respecting the minimum permissible axle loads. For category $\mathrm{N}$ vehicles under Council Directive 96/53/EC the weight borne by the driving axle must not be less than $25 \%$ of the total laden weight of the vehicle or vehicle combination. By the Government Regulation of Slovak Republic 349/2009 Z.z. which is adopting Council Directive 96/53/EC, also the weight on the steering axle must not fall below $20 \%$ of the gross vehicle weight. The cargo is loaded correctly if its centre of gravity on the diagram is in the area bounded by the curves A, B, C, D. The curve of the minimum permissible rear axle load is not shown in the diagram. It limits this area only in specific vehicles, because the rear axle relief can cause only the load placed in front of the front axle.

On the load distribution diagram of the used car, the area of the correct load centre of gravity location is bounded by curves A, B, C. In the first case, the load was placed at the maximum permissible front axle load limit. Load in the 2 nd and 3rd situation is in the area bounded by the curves, meaning that the vehicle is in both cases in an ideal operating load. In the fourth situation, the largest total laden weight of the vehicle was slightly exceeded, as it can be seen on the diagram where the 4 th point is just above the maximum pay-mass line.

\section{Results}

For the measurement purposes, the braking sections have been selected from the time to develop fully brake effect to the stopped vehicle. The Driver response time and brake effect delay time were not taken into account as the weight and load distribution are not related to them. During the tests, these parameters were measured: MFDD $\left(\mathrm{m} . \mathrm{s}^{-2}\right)$, initial speed $\left(\mathrm{km} . \mathrm{h}^{-}\right.$ ${ }^{1}$ ), braking distance $(\mathrm{m})$ and braking time (s).

Table 1. Average measured values. Source: authors

\begin{tabular}{|c|c|c|c|c|}
\hline & $\begin{array}{l}\text { Initial speed } \\
\left(\mathrm{km} \cdot \mathrm{h}^{-1}\right)\end{array}$ & $\begin{array}{l}\text { MFDD } \\
\left(\mathrm{m} \cdot \mathrm{s}^{-2}\right)\end{array}$ & $\begin{array}{l}\text { Brake } \\
\text { distance } \\
\text { (m) }\end{array}$ & $\begin{array}{l}\text { Braking } \\
\text { time (s) }\end{array}$ \\
\hline \multirow{3}{*}{$\begin{array}{l}\text { 1. situation } \\
39 / 99 / 47 *\end{array}$} & 40 & 5.51 & 12.68 & 2.23 \\
\hline & 64 & 5.18 & 33.27 & 3.60 \\
\hline & 84 & 4.63 & 58.22 & 5.06 \\
\hline \multirow{3}{*}{$\begin{array}{l}\text { 2. situation } \\
39 / 79 / 63 *\end{array}$} & 40 & 5.98 & 11.51 & 2.06 \\
\hline & 64 & 5.19 & 31.31 & 3.49 \\
\hline & 82 & 5.54 & 48.86 & 4.39 \\
\hline \multirow{3}{*}{$\begin{array}{l}\text { 3. situation } \\
71 / 80 / 81 *\end{array}$} & 41 & 5.97 & 12.28 & 2.17 \\
\hline & 64 & 5.63 & 29.91 & 3.36 \\
\hline & 82 & 5.76 & 48.32 & 4.27 \\
\hline \multirow{3}{*}{$\begin{array}{l}\text { 4. situation } \\
103 / 86 / 95 \text { * }\end{array}$} & 42 & 5.61 & 13.41 & 2.31 \\
\hline & 65 & 5.89 & 30.50 & 3.33 \\
\hline & 81 & 6.10 & 44.78 & 3.94 \\
\hline
\end{tabular}

*Percentage of used load in order: payload of the vehicle / maximum permissible front axle load / maximum permissible rear axle load;

Table data was used to determine the dependence between axle load and MFDD - the quantity

characteristic of the braking deceleration. 


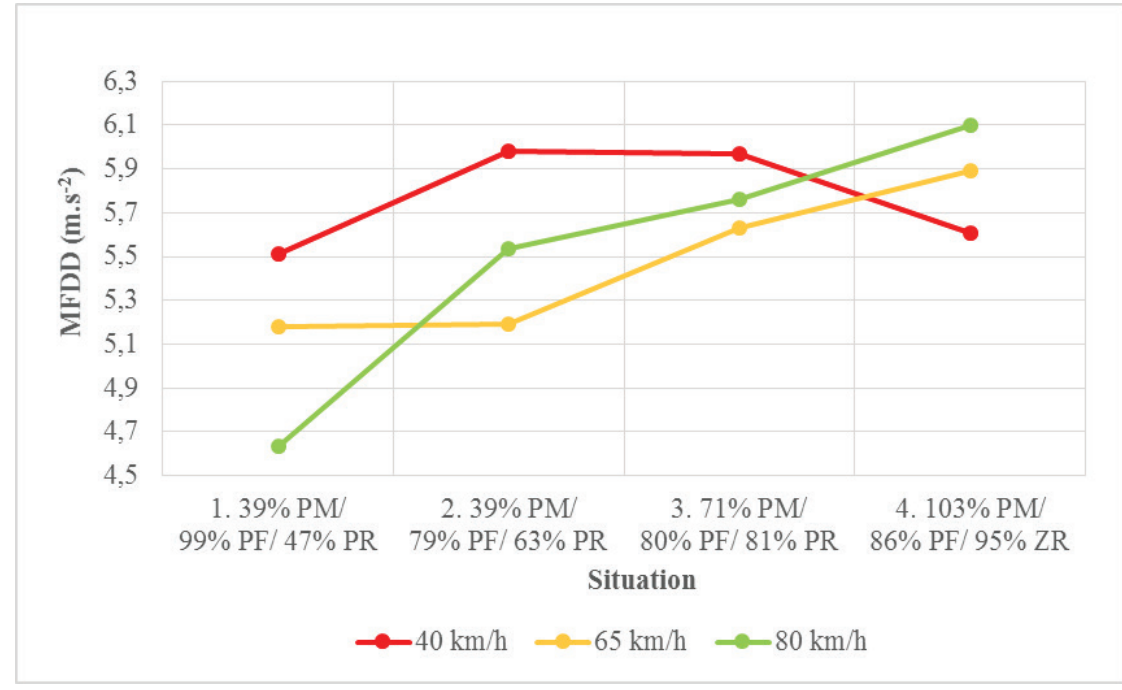

Fig. 5. Dependence of MFDD on axle load. Source: authors

Legend:

PM - pay-mass of the vehicle

$\mathrm{PF}$ - maximum permissible front axle load

$\mathrm{PR}$ - maximum permissible rear axle load

There are large differences in MFDD in individual initial speeds. Spread of braking decelerations by initial speed was the highest in the 1 st situation $-16 \%$. On the contrary, the lowest spread of deceleration was recorded in the 3rd case - only $6 \%$. It is true that with an increase in the initial speed, the change in MFDD is also increasing with a various load. Lower initial speeds are probably an exception; in this situation it is the speed of $40 \mathrm{~km} \cdot \mathrm{h}^{-1}$ where no clear dependence of braking deceleration on the change of axle load has been confirmed. However, it has been found out, that at higher initial speeds the braking deceleration is also increasing with increasing of the rear axle load.

While at the maximum front axle load, the MFDD is the highest at the lowest initial speed and the lowest at the highest initial speed, at the maximum rear axle load the situation is the opposite one.

By averaging the MFDD of all initial speeds and selecting one MFDD for each situation, we draw further conclusions.

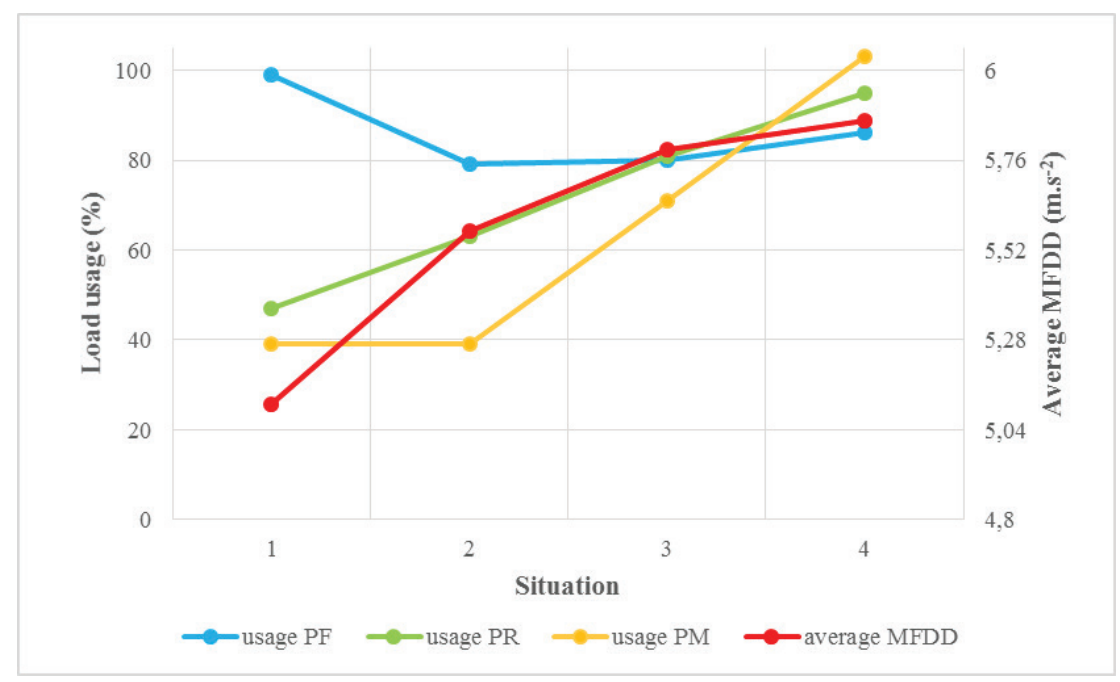

Fig. 6. Influence of load usage on MFDD. Source: authors 
Better deceleration is achieved with the axles of the vehicle loaded more evenly. This fact is confirmed by the third and fourth situation with the highest achieved results, with an ideal load distribution ( $80 \%$ front axle load, $81 \%$ rear axle load) in the 3rd case. In particular, by comparing the first and the second case with the same total vehicle weight, but with a cargo located diametrically differently, we gain the notion that the more evenly the load is on the axles, the higher the braking deceleration is. In the 4th situation the MFDD was higher than in the third situation but the weight distribution was less uniform than in the third case. Based on that, it can be concluded that the increase of the MFDD depends also on the weight above the rear axle.

In contrast to the highest MFDD values in the 3rd and the 4th situation, the lowest braking deceleration was in the 1st case where the mass was concentrated mainly on the front steering axle and it was even higher during braking due to the torque changing axle load induced by the inertia of the centre of gravity. In this context, the role of the height of the centre of gravity is also worth mentioning, since the higher the centre of gravity is, the greater the torque changing axle load is created. During braking, this torque causes an increase of mass on front axle and a drop of mass on the rear axle. When placing a cargo on a loading surface, it is therefore necessary to consider the braking that may result into this overload and it is also important not to place the cargo in the way that the load caused by it would be brought to the maximum permissible front axle load.

In the case of the maximum front axle load, the braking deceleration was decreasing with the increasing initial speed. This means that the faster the vehicle was at the start of the braking, the greater the deceleration drop occurred.

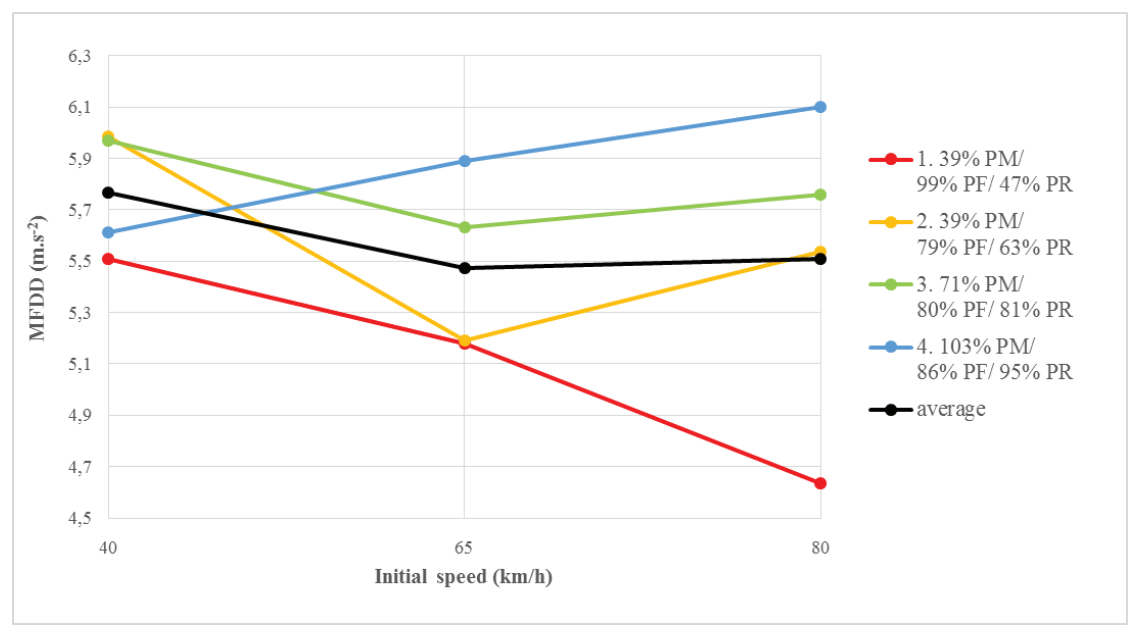

Fig. 7. Dependence of MFDD on initial speed. Source: authors

In situations no. 2 and 3 , it is possible to see a similar decrease in deceleration, but only to an initial speed of $65 \mathrm{~km} \cdot \mathrm{h}^{-1}$. The decrease is smaller the greater the mass on the rear axle is. In the subsequent increase of the initial speed the deceleration slows. The unambiguous braking deceleration was recorded at the maximum rear axle load when the deceleration raised with increasing of initial speed. From the above findings it follows that the braking deceleration chiefly growth with the additional rear axle load, with the exception of the low initial speeds, when an unknown measurement error could also occurred. The exception does not apply to the equal load of both axles where a high braking deceleration was achieved at all initial speeds. 


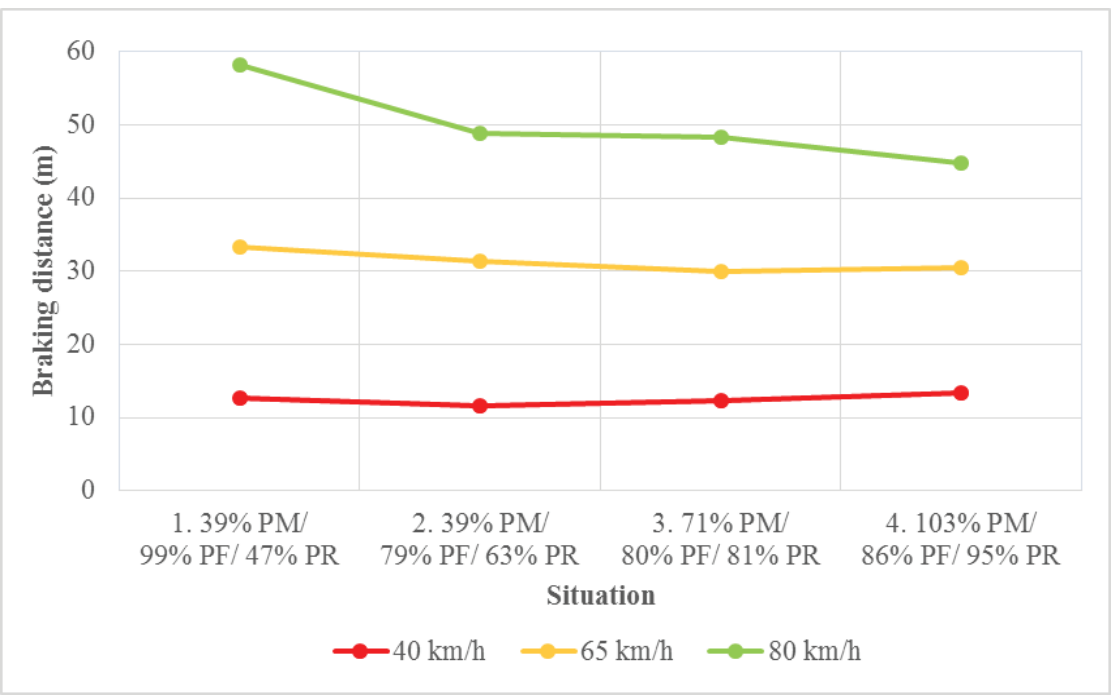

Fig. 8. Dependence of braking distance on axle load. Source: authors

At the lowest initial speed, the shortest braking distance was when the vehicle was loaded with just 1 tonne cargo placed directly above the drive axle. At an average initial speed of $65 \mathrm{~km} \cdot \mathrm{h}^{-1}$, the braking distance is reduced with a more uniform load on each axle. At the highest initial speed, the braking deceleration increases with increasing rear axle load, the difference being almost $15 \mathrm{~m}$ when comparing the braking distance with the maximum front axle load and the maximum rear axle load. In general, it is possible to conclude that the path needed to stop the vehicle is the shorter the greater the load on the rear axle. This fact also confirms the comparison of the first and second situations when the vehicle had an identical gross weight but the load focused in one case on the front and the second on the rear axle.

\section{Conclusions}

The results reveal that not only the gross weight of the vehicle, but also the cargo location on the vehicle's loading surface influences the braking process. It has been found that higher load on the rear axle (as opposed to higher front axle load) favourably influences the braking deceleration of the car, helping to reduce the braking distance. The braking distance difference was greater the faster the vehicle was at the moment when deceleration began raise. These facts accompany the peculiarities at a low initial speed. The same use of maximum permissible axle load had a much clearer effect on braking deceleration. In a case of ideal axle load was achieved high braking deceleration at each initial speed. It could be inferred that when placing the cargo on the loading surface of the vehicle, it is important to place it so that all axles of the vehicle are evenly loaded, making it much more convenient to place the load on the rear axle than on the front.

Surprising results were obtained when investigating the effect of the initial speed. At the lowest initial speed was achieved highest braking deceleration with the centre of gravity closer to the front axle, and the lowest braking deceleration was reached by the vehicle with the most rear axle loaded. Exactly the opposite situation occurred at the highest initial speed when the centre of gravity approaching of the front axle adversely affected the braking deceleration.

This paper is supported by the research project "From horse-drawn railway to intermodal transport" within Visegrad Fund. 


\section{References}

1. Council Directive 96/53/EC, Available online: http://eur-lex.europa.eu/legalcontent/EN/TXT/HTML/?uri=CELEX:01996L0053-20150526\&from=SK (1996)

2. Goverment Regulation of Slovak Republic 349/2009 Z.z., Available online: https://www.slov-lex.sk/pravne-predpisy/SK/ZZ/2009/349/ (2009)

3. J. Mašek, L. Černá, J. Čamaj, Horizonty železničnej dopravy - International conference, 159-173 (Strečno, Slovakia, 2014)

4. J. Gašparík, J. Grenčík, P. Meško, V. Zitrický, V. Lupták, Mechanika v železničnej doprave, 278 p. (University of Žilina, Slovakia, 2016)

5. J. Vrabel; J. Jagelcak; J. Zamecnik, J. Caban, Transbaltica 2017 - 10th International Scientific Conference: Transportation Science and Technology, 89-99 (Procedia Engineering 187, Vilnius, Lithuania, 2017), DOI: 10.1016/j.proeng.2017.04.354

6. B. Sarkan; O. Stopka; J. Gnap, J. Caban, Transbaltica 2017 - 10th International Scientific Conference: Transportation Science and Technology, 775-782 (Procedia Engineering 187, Vilnius, Lithuania, 2017), DOI: 10.1016/j.proeng.2017.04.437

7. J. Lizbetin; O. Stopka; F. Nemec, Transport Means 2016 - 20th International Scientific Conference on Transport Means, 151-155 (Juodkrante, Lithuania, 2016)

8. P. Kohút, R. Jurina, J. Ondruš, 25th Annual Congress of EVU: proceedings: 20-22, 263-275 (2016)

9. V. Rievaj, F. Synák, Scientific journal of Silesian university of technology: Series transport = Zeszyty naukowe Politechniki Śląskiej: Transport 94, 187-197 (2017)

10. D. Barta, M. Mruzek, D. Kalincak, BulTrans: anniversary scientific conference on aeronautics, automotive and railway engineering and technologies, 54 -57 (Sofia, Bulgaria, 2013)

11. J. Grenčík, P. Volna, M. Mikolajčík, Autobusy: technika, eksploatacja, systemy transportowe 6, 881-885 (2016)

12. D. Földes, C. Csiszár, ICTTE 2016 - International Conference for Traffic and Transport Engineering, 533-540 (Belgrade, Serbia, 2016)

13. T. Figlus, M. Stańczyk, Metalurgija 55, 75-78 (2016) 